\title{
LDL-induced NLRC3 inflammasome activation in cardiac fibroblasts contributes to cardiomyocytic dysfunction
}

\author{
PENG WANG ${ }^{1}$, WENBO ZHANG ${ }^{1}$, ZHEN FENG $^{1}$, JIAN ZHANG $^{2}$, YING SUN $^{1}$ and WEI ZHANG ${ }^{2}$ \\ Departments of ${ }^{1}$ Cardiology and ${ }^{2}$ Gastroenterology, Feicheng Mining Center Hospital, Feicheng, Shandong 271600, P.R. China
}

Received May 28, 2020; Accepted February 10, 2021

DOI: $10.3892 / \mathrm{mmr} .2021 .12165$

\begin{abstract}
Heart failure (HF) is a progressive myocardial disease that affects pulse rate. Notably, chronic inflammation serves a crucial role in cardiac dysfunction and HF. Appropriate cardiomyocyte-fibroblast communication is essential for cardiac function. In addition, cardiac fibroblasts (CFs) are the main cellular population in the cardiac microenvironment; therefore, determining the role of CFs in HF progression and the associated molecular basis is important. In the present study, ELISAs were performed to detect inflammatory factors in the sera of patients with $\mathrm{HF}$ and their association with $\mathrm{CF}$ activation was analyzed using Pearson's correlation coefficient. The mechanism underlying the proinflammatory phenotype of CFs was investigated via western blotting. Notably, the levels of IL10 and TNF- $\alpha$ were significantly increased in the sera of patients with HF. Further analysis revealed that CFs were extensively activated in the cardiac tissues of patients with $\mathrm{HF}$ and released excessive amounts of cytokines, which could impair the viability of cardiomyocytes. Moreover, low-density lipoprotein (LDL)-induced NLRC3 inflammasome was activated in CFs, which gave rise to proinflammatory phenotypes. Targeting LDL in CFs significantly improved the functioning of cardiomyocytes and inhibited apoptosis. These findings highlighted the critical role of LDL in inflammasome activation; to the best of our knowledge, the present study is the first to reveal that $\mathrm{CF}$-induced microenvironmental inflammation may suppress cardiomyocyte viability. The present study established the cellular basis for $\mathrm{CF}$ activation during HF progression and provided information on the cellular interactions important for HF treatment.
\end{abstract}

Correspondence to: Dr Wei Zhang, Department of Gastroenterology, Feicheng Mining Center Hospital, 329 Shengdao, Feicheng, Shandong 271600, P.R. China

E-mail: zhangwei20200512@163.com

Key words: heart failure, cardiac fibroblasts, NLRC3 inflammasome, low-density lipoprotein

\section{Introduction}

Heart failure (HF), also known as congestive HF, occurs when the cardiac muscles cannot pump enough blood and oxygen to support other systems (1). HF was considered a contributing cause of 1 in 8 deaths in the United States in 2017 (2). HF is a detrimental and progressive pathological condition, which seriously affects the daily life of patients. Patients with HF present a stage-related continuous decline in exercise tolerance that disrupts the ability to function independently (3). In the severe or acute stages of HF, the associated complications, including edema, dyspnea or infection, can result in death (4). At present, there is no effective treatment to cure HF or prevent cardiomyocytes from constant injury. The existing medications for cardiac dysfunction may only temporarily improve symptoms or slow the rate of decline (5). Several factors associated with $\mathrm{HF}$, including narrowed coronary arteries or hypertension, gradually leave the heart too weak to pulse efficiently. The majority of patients with HF concurrently suffer from hyperlipemia, which is considered the most common cause of cardiovascular disease (6). It was previously suggested that an important way to prevent HF may be to target lipid metabolism (7). A deeper understanding of the biological behaviors and molecular basis of $\mathrm{HF}$ is required to develop therapeutic strategies.

The cell types within the heart include cardiomyocytes, cardiac fibroblasts (CFs), vascular smooth muscle cells and endothelial cells. CFs serve critical roles in supporting normal cardiac function and in pathological remodeling of cardiac tissue, including during HF (8). CFs have various functions, including the synthesis and deposition of inflammatory factors and cell-cell communications with other cellular populations (9). In a recent study, fibroblast activation was reported to contribute to shaping the microenvironment of cardiac tissues during cardiac dysfunction (10). Under such conditions, CFs have been shown to exert proinflammatory activity, which has been identified to correlate with disease escalation. Notably, cardiomyocytes make up $\sim 40 \%$ of the total cell population in cardiac tissues, whereas CFs account for up to $60 \%$ intermingling with cardiomyocytes (11). The cross-talk between these two populations can be regulated by direct cell-cell contact via microtubules and by indirect interactions via a wide range of cytokines $(11,12)$. Therefore, targeting CFs may be considered a novel therapeutic approach to treat $\mathrm{HF}$. 
Inflammasomes have been reported to be crucial for their roles in cardiovascular disorders, neuroinflammation, tumorigenesis and host defense against pathogenic invasion (13-15). An inflammasome is assembled in response to pathogeneses or tissue damage by the Nod-like receptor protein or absent in melanoma 2-like receptors (16). Numerous proinflammatory cytokines, such as IL1 $\beta$, IL10 and IL18, and pyroptosis are induced by inflammasome activation (17). Inflammasomes regulate innate immunity, particularly by acting as platforms for activation of caspase-1, caspase-8, caspase-11 and IL1R-associated kinase. The role of the innate immune system has been identified in the etiology of chronic inflammation in HF. Previously, the best-studied inflammasome, the NLRP3 inflammasome, was revealed to be activated in cardiomyocytes during HF and produced a set of cytokines to promote inflammation (18). However, it remains poorly understood as to whether CFs undergo inflammasome activation during cardiac dysfunction. A recent study indicated that lipid metabolism was closely associated with inflammasome functions (19). Hyperlipemia has consistently been identified to be associated with severe outcomes, including the development of HF, mortality and other cardiovascular events, and low-density lipoprotein (LDL) is considered the most common risk factor (6). However, how hyperlipemia and LDL may influence cardiomyocyte function remains unclear. The present study revealed that the LDL-induced NLRC3 inflammasome was extensively activated in the CFs of patients with $\mathrm{HF}$, which resulted in the release of excessive amounts of IL10 and TNF- $\alpha$, thus impairing the viability of cardiomyocytes and promoting neonatal cardiomyocytes apoptosis. Inhibition of the LDL-induced inflammasome proved beneficial and exerted protective effects on cardiomyocytic function, thereby providing a novel target for therapeutic intervention.

\section{Materials and methods}

Patients and samples. Serum samples were collected from 62 patients with HF (mean age, 71.2 years; age range, 57-93 years; male: Female $=0.63: 1$ ) and 20 healthy controls (age range, 50-87 years; male: Female $=0.67: 1)$ at the Department of Cardiology, Feicheng Mining Center Hospital (Feicheng, China) between October 2015 and June 2020. The diagnosis and classification of HF was conducted according to the Framingham criteria (20). None of the patients had received treatments prior to blood collection. The patient information, including general characteristics, stages and prognosis, was obtained from the medical records or outpatient follow-up records, and is summarized in Table I. In addition, three left ventricle (LV) samples were collected from donors with HF following death and three LV samples were obtained from donors dying of injurious accidents (age range, 37-61 years; male: Female=2:1) between January 2015 and March 2019 at Feicheng Mining Center Hospital, (Feicheng, China). The specimens were immediately frozen in liquid nitrogen and stored until further study. For IHC staining, tissues were embedded in paraffin. The samples were numbered as 'type (HF or control) + pathology no. + region (LV) + section no.', such as HF-15328-LV1. Written informed consent for use of LV tissues was provided by the dying donors themselves or their family members. The aforementioned procedures were approved by the Research Ethics Committee of Feicheng Mining Center Hospital. All patients provided written informed consent according to the Declaration of Helsinki.

Mice. The C57/BL6 wild type (WT) mice ( $\mathrm{n}=6$; male; age, 3 months; weight, 22-25 g) were acquired from Jackson Laboratory. Mice were housed in the SPF animal room at $26^{\circ} \mathrm{C}$ with $50 \%$ humidity, 12-h light/dark cycles and free access to food/water. The WT mice were treated with lipopolysaccharide (LPS; cat. no. QN0166; Beijing Biolab Technology Co., Ltd.; $4 \mathrm{mg} / \mathrm{kg}$ ) or PBS (control group) via intraperitoneal injection once a day for 3 days. A total of 2 days after LPS treatment, mice without any serious adverse reactions were euthanized using $\mathrm{CO}_{2}$. Anesthesia was induced with $15 \% \mathrm{CO}_{2}$ for 2-3 min and the chamber was then filled with $100 \% \mathrm{CO}_{2}$ at a flow rate of $10-30 \%$ per min for $\sim 10 \mathrm{~min}$. The euthanasia of neonatal pups was via decapitation. Bilateral mydriasis and asystole were used to verify the death of animals. In addition, Dahl salt-sensitive (Dahl/ss) HF mice ( $n=6$; male; age, 3-4 months; weight, 22-25 g) were purchased from Beijing Vital River Laboratory Animal Technology Co., Ltd.. These mice were housed at $26^{\circ} \mathrm{C}$ with $50 \%$ humidity, $12-\mathrm{h}$ light/dark cycles and free access to $0.4 \% \mathrm{NaCl}$ food. The Dahl/ss hypertensive model is a well-established rodent model of salt-sensitive hypertension and congestive HF. At 15 weeks of age, female Dahl/ss/obese mice presented with LV diastolic dysfunction, as determined by marked LV hypertrophy and fibrosis, associated with increased cardiac oxidative stress and inflammation (21). The animal experiments were conducted between November 2018 and September 2019. All animals were maintained at the Laboratory Animal Facility, Feicheng Mining Center Hospital. The animal studies were approved by the Animal Care Committee of Feicheng Mining Center Hospital.

Cells. Cells were isolated as previously reported, with some minor modifications (22). CFs were derived from the adult WT or Dahl/ss mice. Briefly, heart tissues were dissociated using the collagenase II enzyme (cat. no. 17101015; $160 \mathrm{U} / \mathrm{ml}$; Thermo Fisher Scientific, Inc.) at $37^{\circ} \mathrm{C}$ for $30 \mathrm{~min}$. After washing three times, the cell suspension was passed through a Corning ${ }^{\circledR} 70-\mu \mathrm{m}$ cell strainer (Sigma-Aldrich; Merck KGaA). Subsequently, the endothelial cells were removed using magnetic beads according to a previously described protocol (23). Cells were subsequently cultured in a humidified incubator (Thermo Fisher Scientific, Inc.) containing $5 \% \mathrm{CO}_{2}$ at $37^{\circ} \mathrm{C}$ for $1 \mathrm{~h}$. The adherent cells could be identified as CFs based on the morphology via light microscopy. Finally, the CFs were cultured with Dulbecco's modified Eagle's medium (DMEM)-F12 (Gibco; Thermo Fisher Scientific, Inc.) supplemented with $10 \%$ fetal calf serum (FCS; Gibco; Thermo Fisher Scientific, Inc.), L-glutamine (cat. no. G7513; 20 mM; Sigma-Aldrich; Merck KGaA) and penicillin/streptomycin (cat. no. V900929; 100 U/ml; Sigma-Aldrich; Merck KGaA). Cells from passages 1-3 were used for subsequent experiments. When CFs were stimulated by LPS $(1 \mu \mathrm{g} / \mathrm{ml})$ for $6 \mathrm{~h}$ at $37^{\circ} \mathrm{C}$, SBC-115076 (cat. no. SML1712; 10 ng/ml; Sigma-Aldrich; Merck KGaA) was utilized to treat the cells for $24 \mathrm{~h}$ at $37^{\circ} \mathrm{C}$ to inhibit LDL production. 
Table I. Characteristics of patients with heart failure (62 cases).

\begin{tabular}{lcc}
\hline Characteristics & No. $(\%)$ & OR \\
\hline Sex & & 0.66 \\
Male & $24(38.71)$ & \\
Female & $38(61.29)$ & 1.39 \\
Age, years & & \\
$<60$ & $2(3.23)$ & \\
$60-80$ & $37(59.68)$ & \\
$>80$ & $23(37.10)$ & \\
Prognosis & & \\
Alive & $49(79.03)$ & \\
Dead & $13(20.97)$ & \\
Stage & & \\
Mild & $28(45.16)$ & \\
Severe & $34(54.84)$ & \\
IL10 (pg/ml) & & \\
$<3,500$ & $25(40.32)$ & \\
$\geq 3,500$ & $37(59.68)$ & \\
TNF- $\alpha(\mathrm{pg} / \mathrm{ml})$ & & \\
$<3,000$ & $23(37.10)$ & \\
$\geq 3,000$ & $39(62.90)$ & \\
\hline
\end{tabular}

OR, odds ratio.

Neonatal cardiomyocytes were dissociated as previously described (24). Briefly, hearts from 5 days postnatal (P5) mice (born from the WT mice acquired from Jackson Laboratory) were collected, minced and digested using collagenase II for $30 \mathrm{~min}$ at $37^{\circ} \mathrm{C}(160 \mathrm{U} / \mathrm{ml})$. After washing three times, cells were suspended in medium 199 (cat. no. M4530; Sigma-Aldrich; Merck KGaA) with $10 \%$ FCS. The cardiomyocytes were enriched using the pre-plating approach to remove contaminating cells before being seeded in cell culture plates. After 3 days, cells formed a confluent monolayer consisting of $95 \%$ cardiomyocytes pulsing in synchrony, which were used in the subsequent experiments. To assess the viability of cardiomyocytes, the pulses of random cells were counted in 1 min under a light microscope. Neonatal cardiomyocytes were cultured and treated with IL10 at $37^{\circ} \mathrm{C}$ for $24 \mathrm{~h}$ (cat. no. I3019; $1 \mu \mathrm{g} / \mathrm{ml}$; Sigma-Aldrich; Merck KGaA) and TNF- $\alpha$ (cat. no. 654245; $1 \mu \mathrm{g} / \mathrm{ml}$; Sigma-Aldrich; Merck KGaA). The control group was treated with PBS. The supernatant of LPS-stimulated CF cultures was harvested and mixed with neonatal cardiomyocytes (1:1).

Immunohistochemistry (IHC). Human or mouse tissues were dehydrated utilizing an ethanol gradient (70, 80 and 95\%; 5 min each) followed by incubation with $100 \%$ ethanol three times for $5 \mathrm{~min}$ per incubation at room temperature. The paraffin-embedded blocks were sliced into $5 \mu \mathrm{m}$ sections and washed in a water bath at $40^{\circ} \mathrm{C}$ for $15 \mathrm{~min}$. Prior to dehydration and paraffin embedding, sections were fixed in $4 \%$ paraformaldehyde (Image-iT ${ }^{\mathrm{TM}}$ Fixation/Permeabilization kit; Invitrogen; Thermo Fisher Scientific, Inc.) at $4^{\circ} \mathrm{C}$ overnight.
The sections were heated in media containing 5\% FBS (Gibco; Thermo Fisher Scientific, Inc.) at $75^{\circ} \mathrm{C}$ for $30 \mathrm{~min}$ to reduce unspecific background. Briefly, to investigate the expression of fibroblast-activated protein (FAP), NLRC3 and LDL in the heart tissues, the prepared sections were stained with antibodies against FAP (cat. no. 66562; 1:200; Cell Signaling Technology, Inc.), NLRC3 (cat. no. ab77817; 1:100; Abcam) and LDL (cat. no. ab14519; 1:100; Abcam) at $4^{\circ} \mathrm{C}$ overnight. The sections were then washed with PBS and incubated with horseradish peroxidase-labeled goat anti-rabbit/or anti-mouse IgG (cat. nos. A0208 and A0216; 1:100; Beyotime Institute of Biotechnology) for $1 \mathrm{~h}$ at room temperature. Staining was evaluated using a light microscope (magnification, $\mathrm{x} 400$ ).

To assess the proliferation of cardiomyocytes, Ki-67 staining was performed. Cells were fixed with $4 \%$ paraformaldehyde at room temperature for $30 \mathrm{~min}$. Cells were incubated with the Ki-67 primary antibody (cat. no. 9449; 1:100; Cell Signaling Technology, Inc.) at $4^{\circ} \mathrm{C}$ overnight, followed by incubation with a horseradish peroxidase-labeled goat anti-rabbit/or anti-mouse IgG (cat. nos. A0208 and A0216; 1:100; Beyotime Institute of Biotechnology) for $1 \mathrm{~h}$ at room temperature. Cells were counterstained with an anti-mouse IgG (H+L) immunofluorescence antibody (cat. no. 4410; 1:200; Cell Signaling Technology, Inc.) and DAPI. The scores of stained cells $\left(\mathrm{Ki}-67^{+}\right)$were calculated by counting the average number of positive cells in 500 nuclei in four random high-power magnifications using a Nikon TE200 fluorescence microscope (magnification, $\mathrm{x} 400$ ).

Both human and mouse tissue were fixed using $10 \%$ formalin at room temperature for 24-36 h. Tissues sections (8- $\mu \mathrm{m}$ thick) were stained using hematoxylin and eosin at room temperature for $3 \mathrm{~min}$, respectively. Staining was observed using a light microscope (magnification, x400).

ELISA. The levels of IL1 $\beta$, IL10, IL18 and TNF- $\alpha$ were examined by utilizing ELISA kits (cat. nos. RAB0275 RAB0244, RAB0267 and RAB1089; Sigma-Aldrich; Merck KGaA). Briefly, $100 \mu \mathrm{l}$ cell culture supernatant or sera was added into duplicate wells and incubated at $37^{\circ} \mathrm{C}$ for $90 \mathrm{~min}$. After washing three times, the indicated primary antibodies (1:200) were added and incubated at $37^{\circ} \mathrm{C}$ for $60 \mathrm{~min}$. Samples were washed a further three times, and $100 \mu \mathrm{l}$ indicated secondary antibodies were added from the ELISA kits and incubated at $37^{\circ} \mathrm{C}$ for $60 \mathrm{~min}$. Following a color reaction with TMB substrate for $15 \mathrm{~min}$ on ice, absorbance was detected at $450 \mathrm{~nm}$ using a microplate reader (800TS; BioTek Corporation).

Western blot analysis. Tissues and cells were lysed in NP-40 splitting buffer (GeneTex, Inc.; pH, 7.4) containing protease-inhibitor cocktail (cat. no. 5871; Cell Signaling Technology, Inc.). Protein concentrations were determined using a NanoDrop spectrophotometer (Thermo Fisher Scientific. Inc.). Proteins ( $5 \mu \mathrm{g}$ ) were separated by SDS-PAGE using $10 \%$ gels and were transferred onto PVDF membranes (cat. no. ISEQ00010; EMD Millipore). Membranes were subsequently incubated with antibodies against IL1 $\beta$ (cat. no. 12703; 1:500; Cell Signaling Technology, Inc.), IL10 (cat. no. 12163; 1:500; Cell Signaling Technology, Inc.), IL18 (cat. no. K002143p; 1:500; Beijing Solarbio Science \& Technology Co.,Ltd.), TNF- $\alpha$ (cat. no. ab183218; 1:500; Abcam), LDL (cat. no. ab14519; 
1:1,000; Abcam), NLRC3 (cat. no. ab77817; 1:1,000; Abcam) and GAPDH (cat. no. ab8245; 1:3,000; Abcam) overnight at $4^{\circ} \mathrm{C}$, and were then probed with goat-anti-rabbit secondary antibodies (cat. no. A0545; $0.4 \mu \mathrm{g} / \mathrm{ml} ; 1: 2,500$; Sigma-Aldrich; Merck KGaA) or rabbit-anti-mouse secondary antibodies (cat. no. A9044; $0.4 \mu \mathrm{g} / \mathrm{ml} ; 1: 2,500$; Sigma-Aldrich; Merck KGaA) for $1 \mathrm{~h}$ at room temperature. The immunoblotting results were visualized using TMB (cat. no. PR1210; Beijing Solarbio Science \& Technology Co., Ltd.).

$R N A$ extraction and reverse transcription-quantitative $P C R(R T-q P C R)$. RNA was isolated using TRIzol ${ }^{\circledR}$ reagent (Invitrogen; Thermo Fisher Scientific. Inc.) according to the manufacturer's protocol. cDNA was synthesized using iScript RT system (Invitrogen; Thermo Fisher Scientific, Inc.) and $2 \mu \mathrm{g}$ RNA according to the manufacturer's protocol. mRNA expression levels were determined using the iQ SYBR Green Supermix kit (Bio-Rad Laboratories, Inc.) and the Bio-Rad iQ5 Multicolor Real-Time PCR detection system (Bio-Rad Laboratories, Inc.), and were normalized to the mRNA expression levels of $G A P D H$. qPCR was performed based on the following conditions: Initial denaturation at $95^{\circ} \mathrm{C}$ for $5 \mathrm{~min}$; followed by 35 cycles at $95^{\circ} \mathrm{C}$ for $30 \mathrm{sec}$ and $60^{\circ} \mathrm{C}$ for $30 \mathrm{sec}$. The $2^{-\Delta \Delta C q}$ method (25) was performed to calculate the fold change and all experiments were conducted at least three times.

The following primer sequences were used: $I L 10$, forward 5'-AGAAGTACCTGGACTCGCCA-3', reverse 3'-CTGGAA GTCCCACTTCATCTGT-5'; TNFA, forward 5'-TCTCCC AGGAGCCGACTG-3', reverse3'-ATCCCAAAAGCGACC CAGTG-5'; $N L R P 1$, forward 5'-GCCTTGGTGAAACCAGGA GA-3', reverse 3'-GCTGCTCTCGATACTGGTCC-5'; NLRP3, forward 5'-CCTGAGCAGCCTCATCAGAA-3', reverse 3'-GCAAGTGCTGCAGTTTCTCC-5'; NLRP4, forward 5'-TGCTGGCCTTCTAACCAACA-3', reverse 3'-CACACC CACATCTCCGATTTC-5'; NLRP5, forward 5'-GGCTGG CTGTGGTTTTCTTG-3', reverse 3'-AGGTGTCTGCTCCTC GAGAT-5'; NLRP8, forward 5'-GAGAGGCTGTCGCAGAGT AA-3', reverse 3'-TTGGTTTTTGCGGAGCATGG-5'; NLRP9, forward 5'-CGGATTTTGGCTTGTTGTGGT-3', reverse 3'-ACAAGATAA ACAGCGGCCCA-5'; NLRP10, forward 5'-TTTGTCGGAGACGGAGAAGC-3', reverse 3'-TAACTG TCCATGCGCTGGTT-5'; NLRP12, forward 5'-GCCAAA GTGCACCCAGAATG-3', reverse 3'-GTCAGCCTCCCTTCC TTCAT-5'; NLRP14, forward 5'-ACCAACACAGACGTGGAT TGT-3', reverse 3'-CAACTGGCATCCTCACAGGT-5'; NOD2, forward 5'-GTACGAGATGCAGGAGGAGC-3', reverse 3'-GCCAATGTCACCCACAGAGT-5'; NLRC1, forward 5'-GTCTGGACGAGTTCCGTTGT-3', reverse 3'-TGTTCC CGTTAAGCTGGTCC-5'; NLRC3, forward 5'-TCTCCGGCA CCTGGATCTTA-3', reverse 3'-GGGCCAAGGATTTAG TGGCT-5'; and GAPDH, forward 5'-GGGTGATGCAGGTGC TACTT-3' and reverse 3'-GGCAGGTTTCTCAAGACGGA-5'.

Flow cytometry (FCM). FCM was performed using the Annexin V-FITC/PI Apoptosis Detection kit (cat. no. C1062S; Beyotime Institute of Biotechnology). Briefly, cells were diluted to $1 \times 10^{5} / \mathrm{ml} /$ per well, dissociated in $1 \mathrm{X}$ binding buffer on ice for $30 \mathrm{~min}$, and were subsequently stained with Annexin V-FITC (10 $\mu \mathrm{mol} / \mu \mathrm{l})$ and propidium iodide (PI; $10 \mu \mathrm{mol} / \mu \mathrm{l})$ in the dark at room temperature for $20 \mathrm{~min}$. The cells were then analyzed using FCM (FACSCanto II; BD Biosciences) and FlowJo software (version 10.0; BD Biosciences). The apoptotic rate was calculated as the percentage of Annexin $\mathrm{V}-\mathrm{FITC}^{+} / \mathrm{PI}^{+}$cells in total cells.

Lentivirus production. Lentiviruses were prepared using LDL short hairpin RNA (shRNA; 5'-CCGGAGTCGCCATTCTCCC TTAATACTCGAGTATTAAGGGAGAATGGCGACTTTTTT G-3'),NLRC3(5'-CCGGACCACGGTCTGCACCATATTACTC GAGTAATATGGTGCAGACCGTGGTTTTTTG-3') or scrambled shRNA (5'-CCTAAGGTTAAGTCGCCCTCGCTCGAG CGAGGGCGACTTAACCTTAGG, CAGGTCGAAGCGGTC GCTAAAAAGCTGGCTCTATTAAACAGGTCG-3') (all Sigma-Aldrich; Merck KGaA), 0.72 pmol pMD2.G, 1.3 pmol psPAX2 (Addgene, Inc.) and $1.64 \mathrm{pmol} \mathrm{Col} \mathrm{plasmids} \mathrm{(Addgene,}$ Inc.) according to the standard protocol. Briefly, Lenti-X 293T packaging cells (China National Infrastructure of Cell Line Resource) were seeded at 3.8 $\times 10^{6} / 6$-well plate in DMEM and incubated at $37^{\circ} \mathrm{C}$ in an atmosphere containing $5 \% \mathrm{CO}_{2}$ for $20 \mathrm{~h}$. The medium was then gently aspirated and $10 \mathrm{ml}$ fresh DMEM containing $25 \mu \mathrm{M}$ chloroquine diphosphate was added to the cells for $5 \mathrm{~h}$ at $37^{\circ} \mathrm{C}$. Subsequently, diluted polyethylenimine (5\%) was added dropwise to the cells while gently flicking the diluted DNA tube. 293T cells were incubated for 15-20 min at room temperature. The transfection mix was transferred to the Lenti-X 293T packaging cells with continuous incubation for $18 \mathrm{~h} 37^{\circ} \mathrm{C}$. Viruses were harvested at 48,72 , and $96 \mathrm{~h}$ post-transfection. The viral supernatant was centrifuged at $500 \mathrm{xg}$ for $5 \mathrm{~min}$ at $4^{\circ} \mathrm{C}$ to pellet any packaging cells that were collected during harvesting. The supernatant was filtered through a $0.45 \mu \mathrm{m}$ PES filter. Murine $\mathrm{CFs}\left(5 \times 10^{6} / \mathrm{ml}\right)$ were infected with the prepared lentivirus at $37^{\circ} \mathrm{C}$ for $\sim 5 \mathrm{~h}$, cultured with complete DMEM, harvested after $72 \mathrm{~h}$, then subjected to RT-qPCR and subsequent experiments.

MTT assay. Neonatal cardiomyocytes (1,000 cells/well) were seeded into 96-well plates (Thermo Fisher Scientific, Inc.) and incubated for $24 \mathrm{~h}$ at $37^{\circ} \mathrm{C}$ in an atmosphere containing $5 \% \mathrm{CO}_{2}$. Cell viability was evaluated by performing an MTT assay. Briefly, $0.5 \mathrm{mg}$ Thiazolyl Blue Tetrazolium Bromide (cat. no. M2128; Sigma-Aldrich; Merck KGaA) was added to each well for $4 \mathrm{~h}$ at $4^{\circ} \mathrm{C}$. After removing the supernatant, $100 \mu \mathrm{l}$ dimethyl sulfoxide (cat. no. 1912433; Johnson \& Johnson Services, Inc.) was added to each well and incubated for $10 \mathrm{~min}$ at the room temperature. The purple mixture in each well was then measured at $490 \mathrm{~nm}$ using a microplate reader (800TS; BioTek Corporation). The inhibition rate (\%) was analyzed using the following formula: [(Control OD490-Experimental OD490)/Control OD490] x100.

Statistical analysis. Data are presented as the mean \pm standard deviation, and were analyzed by Student's t-test using SPSS v.19.0 (IBM Corp.) and GraphPad Prism v.8.0 (GraphPad Software, Inc.). The unpaired t-test was used for comparison between two groups, whereas comparison of mean values between multiple groups was evaluated by one-way ANOVA followed by Student-Newman-Keuls post hoc test. The functional experiments were performed at least three times. The correlation between NLRC3 mRNA expression and IL10 or TNFA mRNA expression was analyzed by Pearson's 
correlation. Logistic regression was performed to analyze the clinical risk factors. $\mathrm{P}<0.05$ was considered to indicate a statistically significant difference.

\section{Results}

CFs are activated during $H F$ resulting in microenvironmental inflammation. An inflammatory microenvironment has been characterized as an important feature of HF (26). To observe the inflammation in patients with $\mathrm{HF}$, a total of 62 patients with HF and 20 healthy controls were included in the current cohort: 28 (45.16\%) patients suffered from mild HF and 34 $(54.84 \%)$ were in the severe stage (Table I). Sera were harvested from these patients and healthy controls to examine the levels of well-known inflammatory factors, including IL1 $\beta$, IL10, IL18 and TNF- $\alpha$. As shown in Fig. 1A, all of these cytokines were elevated in patients with mild and severe $\mathrm{HF}$, and were progressively increased in the severe stage. Furthermore, IL10 and TNF- $\alpha$ were most significantly increased in the severe stage (Fig. 1A; Table I). As evidenced by logistic regression analysis, the expression levels of IL10 and TNF- $\alpha$, as well as age and HF stage, affected the prognosis, which indicated that IL10 and TNF- $\alpha$ could be considered valuable prognostic indicators for patients with HF (Table I).

Similarly, western blot analysis detected higher expression levels of IL1 $\beta$, IL10, IL18 and TNF- $\alpha$ in heart tissues from donors with HF (Fig. 1B). Previously, activated fibroblasts have been reported to represent a common pathological characteristic of cardiac fibrosis and heart dysfunction $(27,28)$. Accordingly, to detect the activation of CFs in the cardiac tissues of HF hearts, the expression of FAP was detected by IHC in human donor samples. A large number of $\mathrm{CFs}\left(\mathrm{FAP}^{+}\right)$ were present across the cardiac tissues of HF donors compared with in the normal controls, which were positively associated with fibrosis in the hematoxylin and eosin staining (Fig. 1C).

To confirm the presence of inflammation in cardiac tissues, LPS was used to treat mice for 3 days and the heart tissues were harvested to examine the mRNA expression levels of ILIO and TNFA. As shown in Fig. 1D, the mRNA expression levels of ILIO and TNFA were upregulated in the heart tissues of LPS-stimulated mice compared with those in the control group, indicating that LPS could induce inflammation. To further identify the role of CFs in the production of IL10 and TNF- $\alpha$, CFs were cultured with LPS stimulation and the supernatant was collected to examine the concentration of IL10 and TNF- $\alpha$. As expected, IL10 and TNF- $\alpha$ were significantly elevated in the LPS treatment group compared with those in the control group (Fig. 1E), which indicated that activated fibroblasts could provide specific inflammatory factors. With the goal of identifying the effects of IL10 and TNF- $\alpha$ on the viability of neonatal cardiomyocytes, cells purified from P5 mice were cultured and treated with IL10 and TNF- $\alpha$. Subsequently, the results of an MTT assay revealed that cell viability was significantly suppressed by these two cytokines (Fig. 1F). Taken together, these data suggested that IL10 and TNF- $\alpha$ derived from the activated CFs may attenuate the viability of cardiomyocytes.

NLRC3 inflammasome is activated in CFs of HF. Having identified fibroblast activation in the heart tissues of patients with
HF, the present study aimed to detect the molecular mechanism underlying the proinflammatory phenotype of CFs. Previous studies reported that inflammasome activation contributed to the release of a wide variety of cytokines, including IL1 $\beta$, IL18 and TNF- $\alpha$ in the absence of cell death $(16,29)$. To detect specific activation of the inflammasome during cardiac dysfunction, RT-qPCR was used to analyze the heart tissues of patients with HF and healthy control donors; the results indicated that the mRNA expression levels of NOD2 and $N L R C 3$ were significantly increased compared with those in the control group (Fig. 2A). By contrast, the expression levels of NLRP1, NLRP3, NLRP4, NLRP5, NLRP8, NLRP9, NLRP12, NLRP14 and NLRC1 were not significantly altered. NOD2 and the NLRP3 inflammasome have been reported to be activated in mesenchymal stromal cells in mice with cardiomyopathy (30). However, it is poorly understood whether CFs undergo NLRC3 inflammasome activation to promote cardiac dysfunction. To address this, fibroblasts were collected from HF model heart tissues (Fig. 2B) and the mRNA expression levels of NOD2 and NLRC3 were examined by RT-qPCR. As shown in Fig. 2C, significant differences existed in NLRC3 mRNA expression. Similar to the results of RT-qPCR analysis, a proportion $(31.2 \%)$ of CFs expressed NLRC3 in the cardiac tissues of HF mouse models (Fig. 2D). In order to ascertain the association between NLRC3 inflammasome activation and the proinflammatory phenotype, a correlation analysis was performed using RT-qPCR data; a positive correlation was detected between NLRC3 and IL10/TNFA mRNA expression (Fig. 2E). To explore the role of NLRC3 in IL production, CFs were infected with a lentiviral plasmid containing a NLRC3-specific shRNA, in order to reduce the expression of NLRC3 (Fig. 2F). After NLRC3-deficient cells were treated with LPS for $72 \mathrm{~h}$, the mRNA expression levels IL10 and TNFA were revealed to be downregulated, demonstrating inactivation of CFs lacking NLRC3 (Fig. 2G). Collectively, these data suggested that NLRC3 inflammasome activation may contribute to the proinflammatory features of CFs.

$L D L$ is required for NLRC3 inflammasome activation in CFs. Previously, lipid metabolism has been reported to be involved in the progression of chronic inflammation (31). LDL, as a modulator for lipid metabolism, serves a critical role in activating broadly diverse pathways associated with inflammation and fibrosis (32). A recent study demonstrated that the level of LDL was highly increased in activated fibroblasts (33). Therefore, the present study aimed to determine whether the expression of LDL could induce NLRC3 inflammasome activation. Diffuse LDL immunostaining was observed in the cardiac tissues of patients with $\mathrm{HF}$, supporting the evidence linking LDL with cardiac dysfunction (Fig. 3A). Moreover, a strong correlation between $L D L$ and $N L R C 3$ expression was determined based on the RT-qPCR (Fig. 3B), which was further indicated via immunoblotting of human HF heart tissues (Fig. 3C). To further detect the role of LDL in NLRC3 inflammasome activation, CFs were infected with LDL shRNA or scrambled shRNA to knockdown LDL expression (Fig. 3D). When treating LDL-deficient cells with LPS, the results of RT-qPCR revealed that the mRNA expression levels of NLRC3, ILIO and TNFA were significantly suppressed compared with those in the control group (also treated with 
A

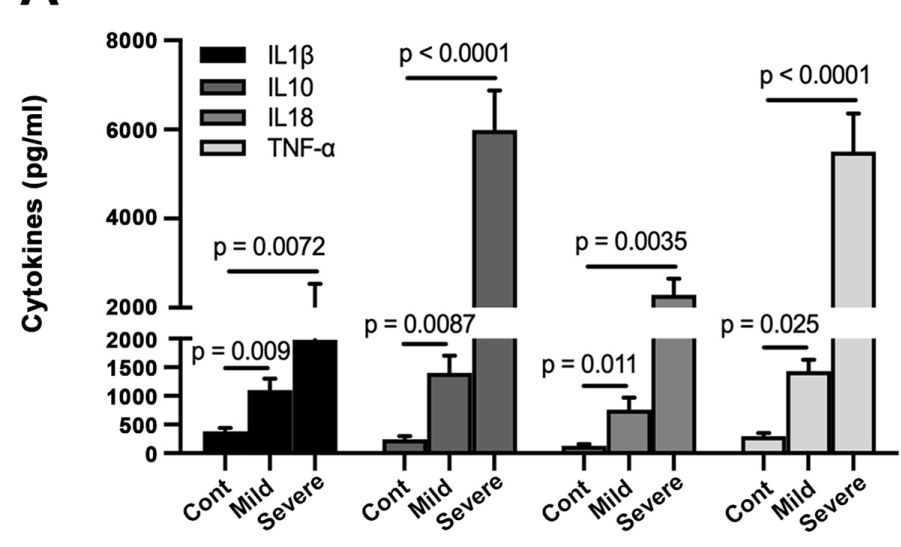

C
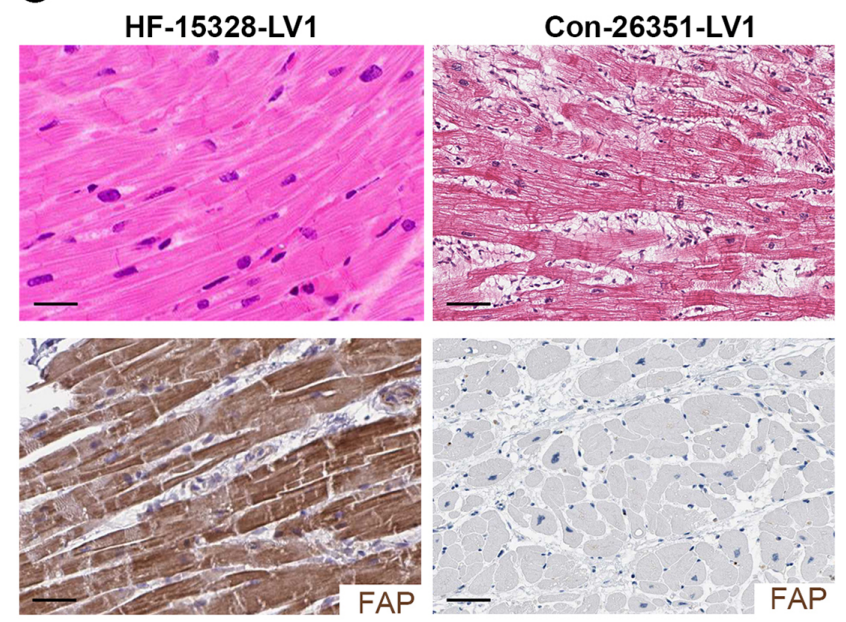

$\mathbf{F}$

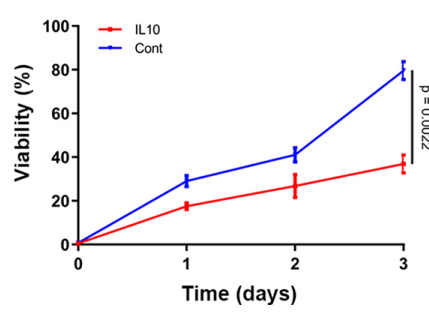

B

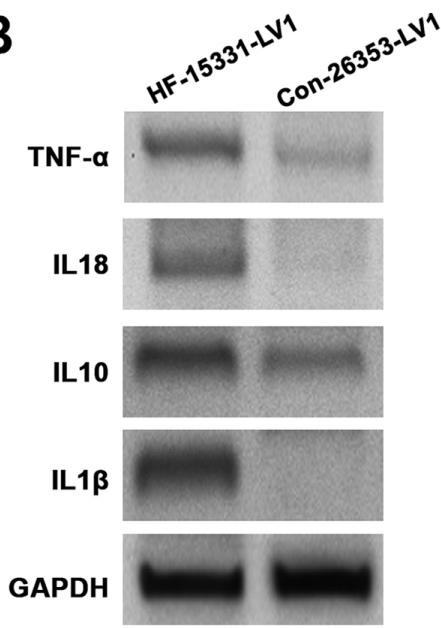

D

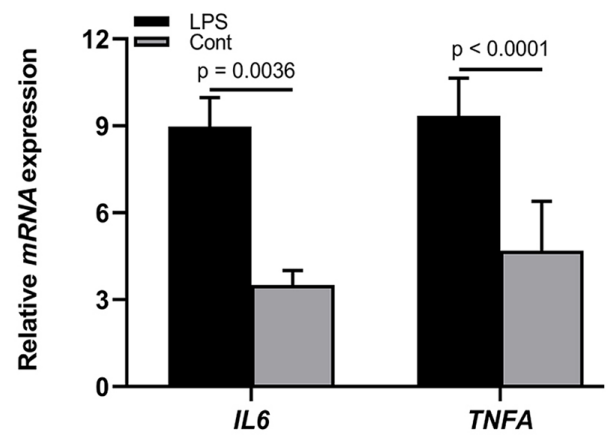

E

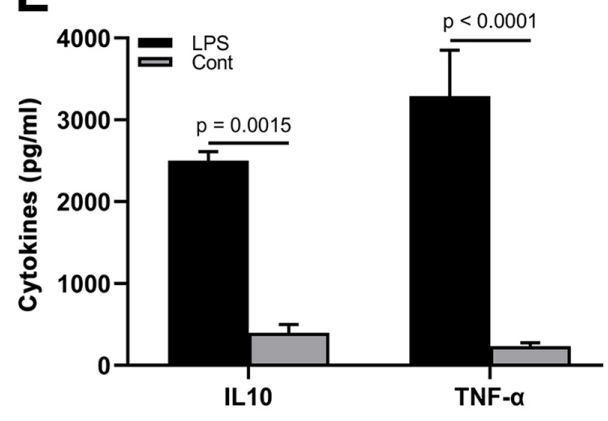

Figure 1. CFs are activated in the heart tissues of patients with HF. (A) Levels of IL1 $\beta$, IL10, IL18 and TNF- $\alpha$ in the sera from healthy controls (n=20), and patients with mild $(n=28)$ and severe $(n=34) H F$, as determined by ELISA. (B) Protein expression levels of IL1 $\beta$, IL10, IL18 and TNF- $\alpha$ in myocardial samples from a control individual (Con-26353-LV1) and patient with HF (HF-15331-LV1), as determined by western blotting. GAPDH was used as the internal control. (C) Hematoxylin and eosin staining and immunohistochemical staining of FAP in myocardial samples from a control individual (Con-26351-LV1) and patient with HF (HF-15328-LV1) (scale bar, $10 \mu \mathrm{m}$ ). (D) mRNA expression levels of IL10 and TNFA in cardiac tissues from LPS-treated mice. (E) Levels of IL10 and TNF- $\alpha$ in the supernatant of CFs treated with LPS. (F) MTT assay showing the viability of neonatal cardiomyocytes treated with IL10 and TNF- $\alpha$. CFs, cardiac fibroblasts; HF, heart failure; FAP, fibroblast-activated protein.

LPS) (Fig. 3E). These findings indicated that LDL may confer proinflammatory signatures to CFs through the NLRC3 inflammasome.

Targeting LDL improves cardiomyocyte function. The aforementioned data indicated that activated CFs may contribute to the progression of cardiac chronic inflammation. The present study investigated whether cardiomyocyte injury could be inhibited by targeting the LDL-induced NLRC3 inflammasome. A proprotein convertase subtilisin/kexin type 9 (PCSK9) inhibitor (SBC-115076) was used to inhibit the levels of LDL in CF cultures (34). Following LPS stimulation, the mRNA expression levels of NLRC3,IL10 and TNFA were significantly suppressed by inhibition of LDL (Fig. 4A). Subsequently, the supernatant of LPS-stimulated CF cultures was harvested and mixed with neonatal cardiomyocytes $(1: 1)$; the results of a subsequent MTT assay revealed that cell viability was reduced by $70 \%$ in the untreated group (Fig. 4B). Ki-67 index was examined by immunostaining and revealed that the expression levels of Ki-67 were decreased in the control 
A

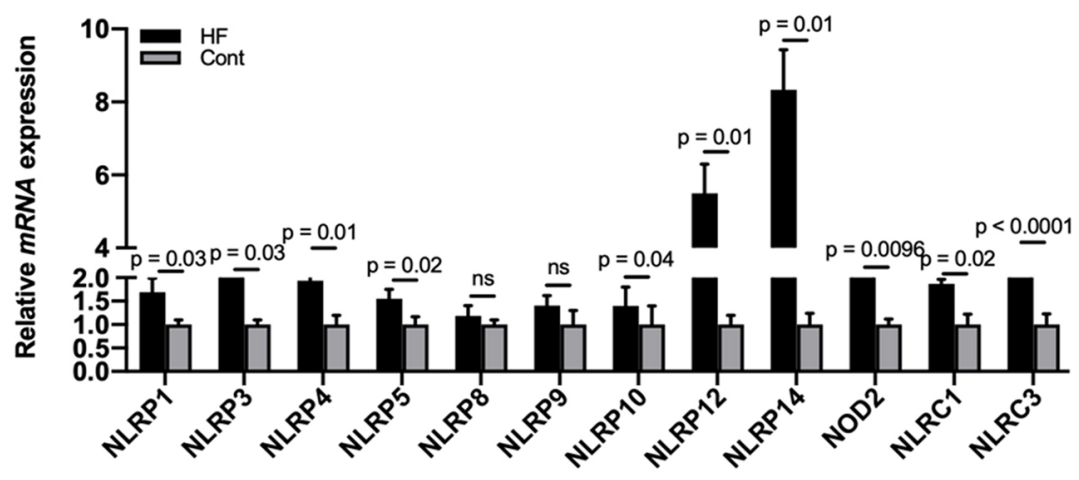

B

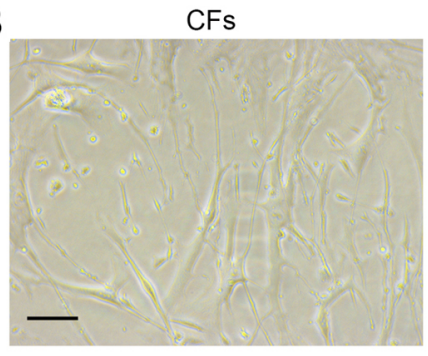

D
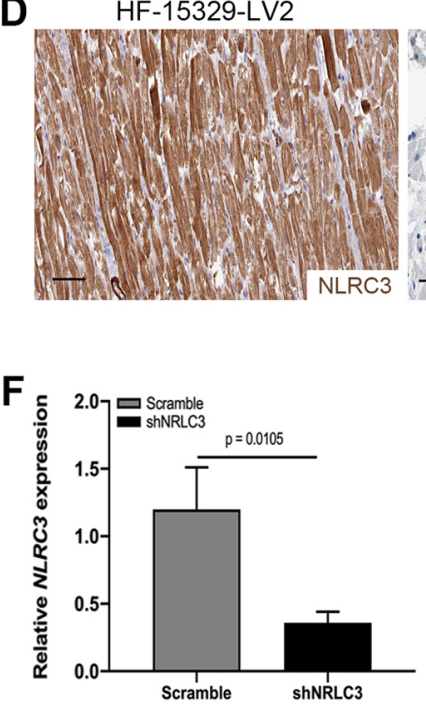

Cardiomyocytes

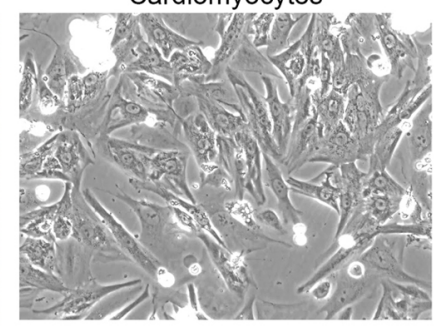

C

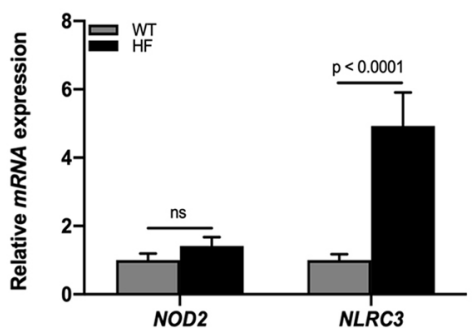

Con-26354-LV3

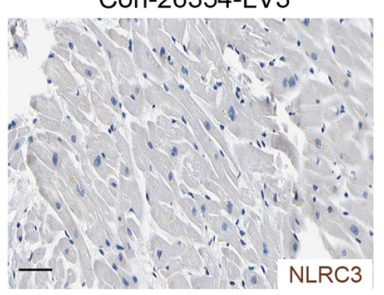

E

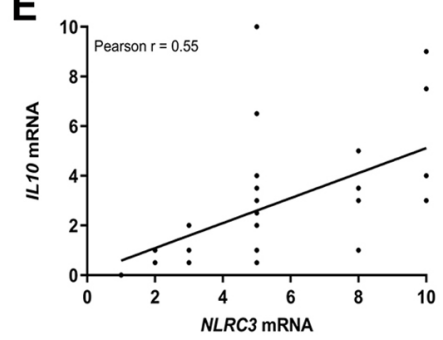

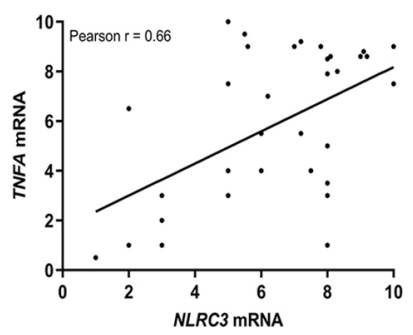

G

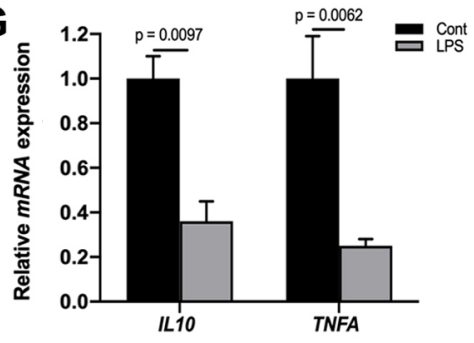

Figure 2. NLRC3 inflammasome is activated in the CFs of patients with HF. (A) RT-qPCR analysis of the expression of inflammasome-associated genes (NLRPs and $N L R C \mathrm{~s}$ ) in myocardial samples from control individuals $(\mathrm{n}=3)$ and patients with $\mathrm{HF}(\mathrm{n}=3)$. (B) Representative images of $\mathrm{CFs}$ and cardiomyocytes $(\mathrm{scale}$ bar, $10 \mu \mathrm{m}$ ). (C) RT-qPCR analysis of NLRC3 mRNA expression in CFs from mice in the LPS treatment or control groups. (D) Immunohistochemical staining of NLRC3 in a myocardial samples from a control individual (Con-26354-LV3) and patient with HF (HF-15329-LV2) (scale bar, $10 \mu \mathrm{m}$ ). (E) Pearson analysis of the correlation between NLRC3 mRNA and ILIO or TNFA mRNA. (F) RT-qPCR analysis of NLRC3 mRNA expression in CFS infected with shRNA-NLRC3 after LPS stimulation. (G) RT-qPCR analysis of IL10 and TNFA mRNA expression in CFs infected with shRNA-NLRC3 after LPS stimulation. CFs, cardiac fibroblasts; HF, heart failure; RT-qPCR, reverse transcription-quantitative PCR; LPS, lipopolysaccharide; shRNA, short hairpin RNA.

group without treatment (Fig. 4C). Most cardiomyocytes were actively proliferating $\left(\mathrm{Ki}-67^{+}\right)$after SBC-115076 treatment (Fig. 4C). When counting the pulse of cardiomyocytes, it was similarly revealed that SBC-115076 treatment significantly improved the viability of cells (Fig. 4D). These data suggested that inhibiting chronic inflammation via targeting LDL may provide beneficial effects on cardiomyocytic function. In addition, when neonatal cardiomyocytes were cultured with the supernatant of LPS-stimulated CFs or with fibroblasts from the hearts of a mouse model of HF, FCM analysis revealed that SBC-115076 treatment markedly inhibited the apoptosis of cardiomyocytes compared with that in the control group
(Fig. 4E and F). These data demonstrated that activated CFs may construct an inflammasome-associated cytokine microenvironment promoting cardiac dysfunction.

\section{Discussion}

HF progresses over time as the cardiac pulse loses power; this results in a decline in exercise tolerance and the dysfunction of other systems, which seriously affects daily life. In the United States, 6.0 million people suffer from HF, and both children and adults can be diagnosed with this disorder; however, the symptoms and clinical management differ. Notably, cardiac 

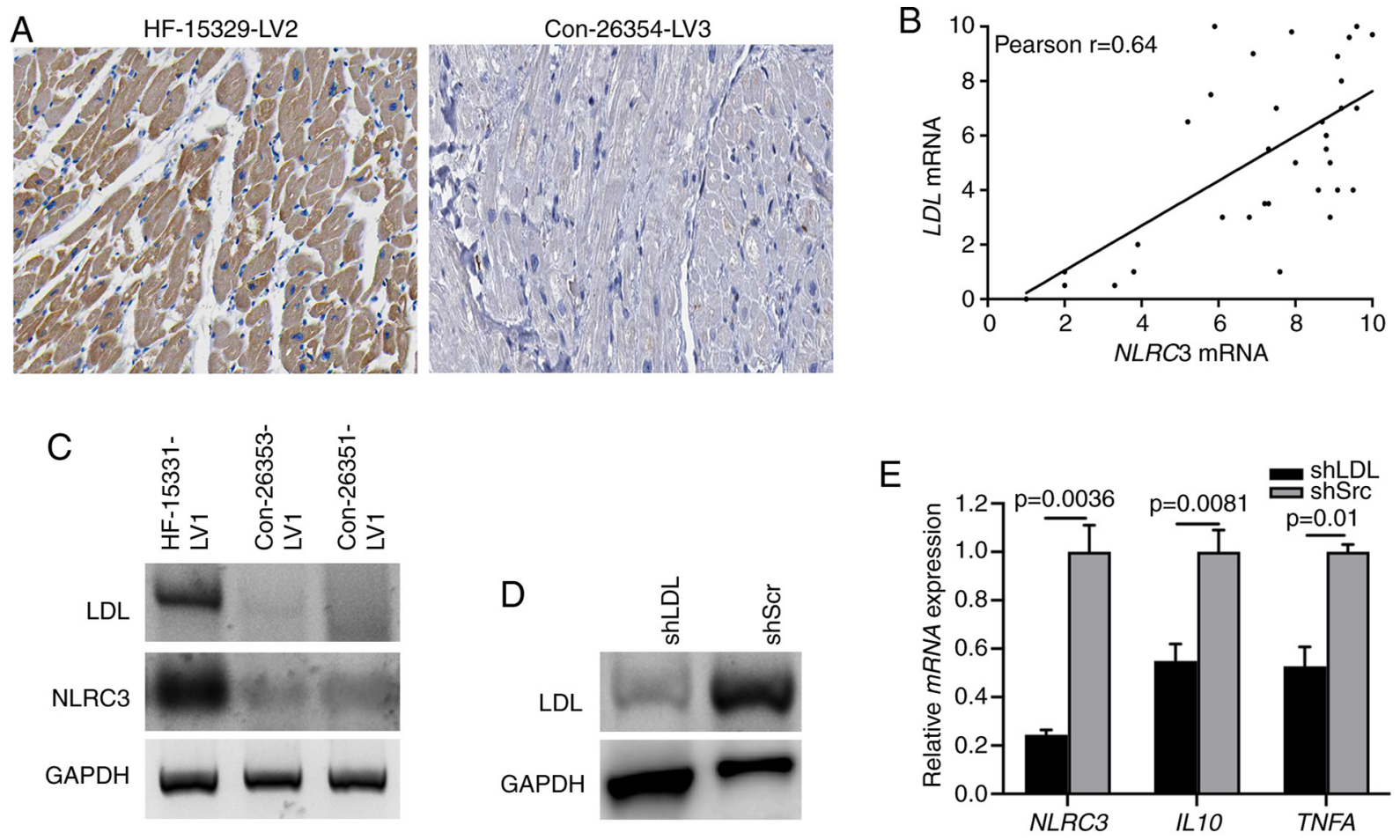

Figure 3. LDL is required for NLRC3 inflammasome activation in CFs. (A) Immunohistochemical staining of LDL in myocardial samples from a control individual (Con-26354-LV3) and patient with HF (HF-15329-LV2) (scale bar, $10 \mu \mathrm{m}$ ). (B) Pearson analysis of the correlation between $L D L$ and $N L R C 3 \mathrm{mRNA}$. (C) Western blot analysis of the expression of LDL and NLRC3 in myocardial samples from control individuals (Con-26353-LV1 and Con-26351-LV1) and patient with HF (HF-15331-LV1). GAPDH was chosen as the internal control. (D) Western blot analysis of the expression of LDL in CFs infected with shLDL and shScr. (E) Reverse transcription-quantitative PCR analysis of NLRC3, IL10 and TNFA mRNA expression in CFs infected with shLDL after LPS stimulation. CFs, cardiac fibroblasts; HF, heart failure; LDL, low-density lipoprotein; LPS, lipopolysaccharide; sh, short hairpin RNA; shScr, scrambled shRNA.

dysfunction is not a normal part of aging nor is it a disease of old age. HF has emerged as the seventh leading cause of death in the United States and $\sim 300,000$ Americans $<60$ years old suffer from mild HF (35). Consistent with these previous findings, the present study reported that age and risk stages affected the prognosis of patients with HF. However, in China, there remains a shortage of systematic databases to comprehensively analyze the features of Chinese patient with HF. The development of a corresponding system may help to improve the diagnosis and treatment of HF.

A well-known risk factor of $\mathrm{HF}$ is cardiovascular events. The majority of patients with HF also suffer from cardiovascular pathophysiological conditions, such as hypertension, coronary heart disease and hyperlipemia. For patients with chronic HF, the cutoff for total cholesterol is between 190 and $200 \mathrm{mg} / \mathrm{dl}$ for the diagnosis of chronic HF (36). Previous retrospective trials have reported that statins may have beneficial effects on a subset of patients with HF, particularly with regards to mortality and disease worsening $(37,38)$. LDL or cholesterol can build up in the walls of arteries and increase the risk of heart disorders. Cholesterol levels should be measured at least once every 2 years for all individuals $>20$ years old (39). After measuring the 10-year risk, doctors will recommend a percentage by which the patient should try to lower LDL levels via improving diet, exercise and medication if necessary (40). In addition to statins, a PCSK9 inhibitor has recently been reported to significantly decrease the levels of LDL (34). In terms of microenvironmental effects, the present study ruled out the molecular basis regarding the correlation between lipid metabolism and HF, and highlighted the contribution of LDL-induced inflammasome activation to cardiomyocytic dysfunction. The proinflammatory phenotype could be partly attributed to this mechanism. Similarly, Stoekenbroek et al (34) identified the TREM2-ApoE pathway as the main mediator of the inflammatory phenotype in microglia in neurodegenerative conditions and indicated that targeting lipid metabolism could restore homeostatic fibrosis components.

HF is currently at the forefront of biomedical research. Scientists have discovered numerous aspects of HF and other cardiovascular diseases, and research advances have provided information on how cardiac pathogenesis affects heart function. Numerous approaches are currently under investigation worldwide, with the aim of better understanding the molecular basis of HF $(41,42)$. Potentially, cholesterol or LDL may lead to chronic inflammation, which is a serious cause of HF progression. When high levels of cholesterol occur in the blood, excessive LDL can seep into the myocardium or arterial inner walls, triggering an inflammatory response and enhancing the activation of numerous cellular components (43). In addition, the deposited cholesterol may rupture and cause cardiovascular events and strokes via blood clots, during which chronic inflammation may have a role. Inflammation has been identified as the link between numerous disorders and conditions, particularly those influencing the cardiovascular and nervous systems (44). In addition to HF or other heart diseases, diabetes, dementia and cancer have been associated with inappropriate and chronic inflammation (45). For example, microglia- or astrocyte-derived inflammatory factors have been reported to 

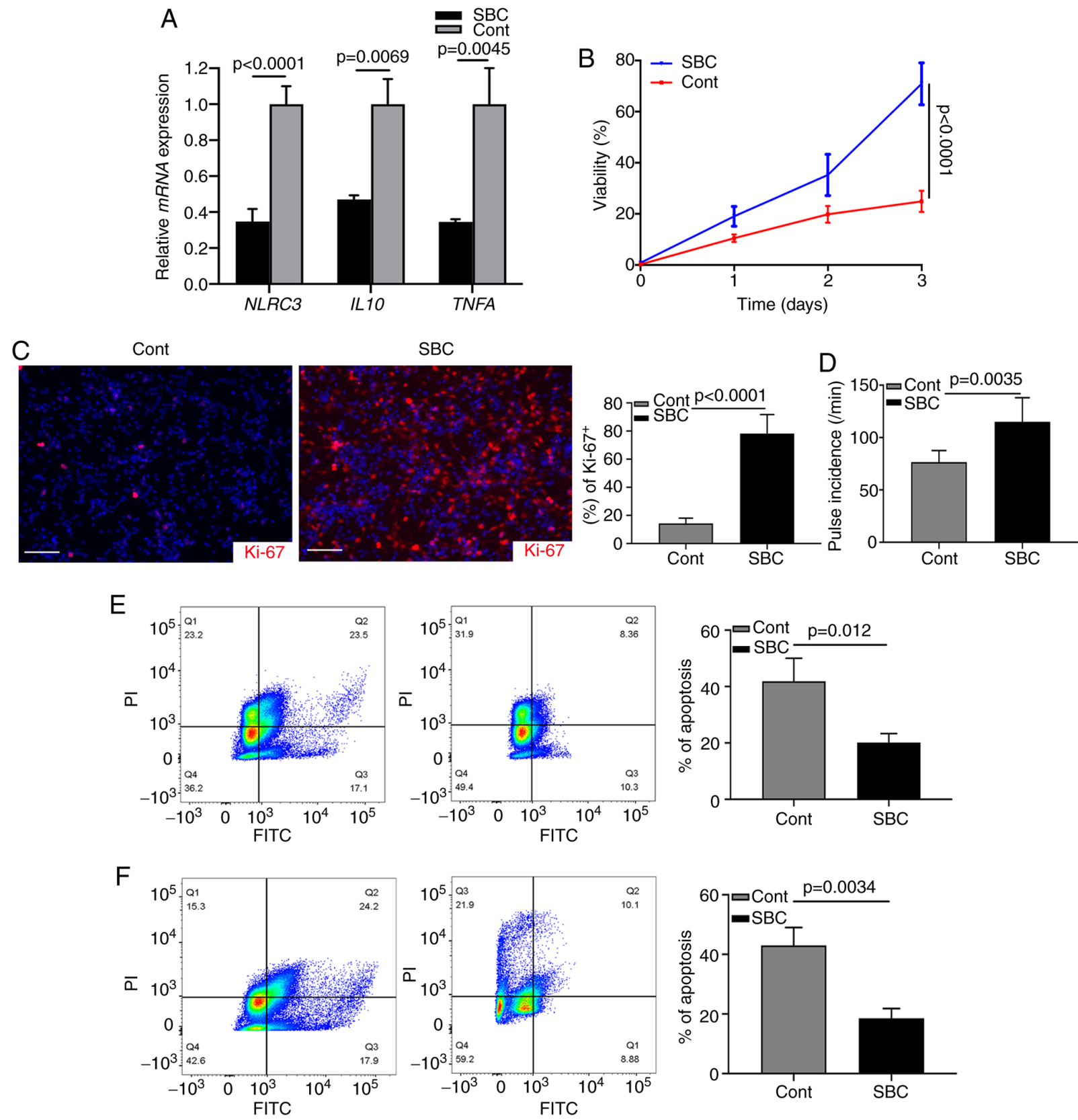

Figure 4. Inhibition of low-density lipoprotein improves the viability of cardiomyocytes. (A) Reverse transcription-quantitative PCR analysis of $N L R C 3, I L 10$ and TNFA mRNA expression in CFs treated with a PCSK9 inhibitor after LPS stimulation. (B) MTT assay was used to determine the viability of neonatal cardiomyocytes cultured with a PCSK9 inhibitor in the presence of LPS-stimulated CF supernatant. (C) Immunostaining of Ki-67 in neonatal cardiomyocytes co-cultured with CFs and treated with a PCSK9 inhibitor (scale bar, $10 \mu \mathrm{m}$ ). (D) Pulse analysis of the viability of neonatal cardiomyocytes co-cultured with CFs and treated with a PCSK9 inhibitor. (E) FCM analysis of the apoptosis of neonatal cardiomyocytes cultured with a PCSK9 inhibitor in the presence or absence of LPS-stimulated CF supernatant. (F) FCM analysis of the apoptosis of neonatal cardiomyocytes cultured in the supernatant of CFs from a mouse model of HF with or without PCSK9 inhibitor treatment. CFs, cardiac fibroblasts; HF, heart failure; LPS, lipopolysaccharide; FCM, flow cytometry; PCSK9, proprotein convertase subtilisin/kexin type 9.

contribute to inhibiting the proliferation of neural stem cells in the hippocampus of patients with Alzheimer's disease (46). Lipid-triggered neuroinflammation has also been reported in the majority of malignant brain tumors, where it may promote progression (47). Both cancer cells and non-malignant stromal cells can exhibit a proinflammatory phenotype with the goal of accelerating tumor growth and resisting chemoradiotherapy (48). Although studies regarding cardio-inflammation have suggested that a number of patients develop hyperlipemia as they age, those with HF tend to develop far more and in a predictable pattern, beginning in the areas important for exercise tolerance. However, the exact role of chronic inflammation in cardiomyocyte dysfunction remains to be completely elucidated, although it has been hypothesized that it may damage pulse function and promote the processes of cardiac fibrosis.

Fibroblasts represent an intrinsic and dynamic cell population in the cardiac microenvironment, which produce cytokines and extracellular matrix components (28). Fibroblast activation exerts both detrimental and beneficial effects on various disorders (42). Appropriate cardiomyocyte-fibroblast 
interactions are essential for cardiac function. In addition, via their effects on stromal components, fibroblasts are involved in cancer proliferation and migration (49). Notably, characterization of the features of CFs may provide comprehensive knowledge of treatment of cardiovascular diseases. Activated CFs are considered a common pathological characteristic of HF. Previous studies have suggested that proinflammation of CFs in HF cardiac tissues may be increased because fibroblast-mediated inflammatory associated pathways are upregulated (10,28). Recently, Sen et al (41) described a novel CF subtype associated with HF by analyzing single-cell transcripts, which suggested further investigation into $\mathrm{CF}$ subgroups using the advanced single-cell technology. The results of the present study demonstrated that CFs were activated in the cardiac tissues of patients with HF. The specifically activated CFs presented a proinflammatory phenotype secreting NLRC3 inflammasome-induced IL10 and TNF- $\alpha$, in order to promote the progression of cardiac dysfunction. These findings highlight the essential roles of CFs in microenvironmental inflammation and may offer more opportunities for future therapeutic strategies.

In the current study, to investigate the mechanism underlying the proinflammatory phenotype of CFs, activation of the NLRC3 inflammasome was detected by analyzing mRNA and protein expression. To further detect the molecular basis of inflammasome activation, CFs obtained from adult mice were manipulated by shRNA technology to determine the critical role of LDL in triggering inflammasome-mediated cytokine production. An inflammatory microenvironment is considered one of the characteristics of HF progression (26). The present findings indicated the important effects of LDL on inducing inflammasome activation during $\mathrm{HF}$ progression, indicating the importance of managing chronic inflammatory reactions in other cardiovascular pathogenic conditions. However, it is still under debate whether inflammasome activation can benefit or impair cardiac functions. Cardiomyocytes function well if they are supported by other cell populations in the microenvironment, including CFs, endothelial cells and immune cells (50). Nonetheless, the molecular basis underlying the communication between cells and cell activation are not well defined. Recently, numerous studies have provided insights into the involvement of newly discovered non-pathological functional signalosome complexes in microenvironmental inflammation, such as inflammasomes, necrosomes and apoptosomes $(29,51)$; in particular, the key roles served by inflammasomes, including NLRC4. In conclusion, the present study demonstrated the crucial role of NLRC3 inflammasome activation in CFs and revealed that CFs-induced inflammation promoted $\mathrm{HF}$ progression.

\section{Acknowledgements}

The authors would like to thank Dr Hai Wang (Feicheng Mining Center Hospital) for providing valuable suggestions about data processing.

\section{Funding}

No funding was received.

\section{Availability of data and materials}

The datasets used and/or analyzed during the current study are available from the corresponding author on reasonable request.

\section{Authors' contributions}

WZ and PW contributed to the conception and design of this study. WZ and PW confirm the authenticity of all the raw data. PW was responsible for the details of experimental performance and performed the experiments. PW, WBZ and WZ performed the histological diagnosis and IHC staining evaluation. JZ and ZF collected and analyzed the clinical data. YS interpreted the pathological data. PW and WZ analyzed the clinical data. PW completed the manuscript, figures and tables. All authors read and approved the final manuscript.

\section{Ethics approval and consent to participate}

The studies involving human tissues were approved by the Research Ethics Committee of Feicheng Mining Center Hospital. All patients provided written informed consent according to the Declaration of Helsinki. Written informed consent for use of LV tissues was provided by the dying donors themselves or their family members. The animal studies were approved by the Animal Care Committee of Feicheng Mining Center Hospital.

\section{Patient consent for publication}

Not applicable.

\section{Competing interests}

The authors declare that they have no competing interests.

\section{References}

1. King KC and Goldstein S: Congestive heart failure and pulmonary edema. In: StatPearls. StatPearls Publishing, Treasure Island, FL, 2021.

2. Ingram DD, Malec DJ, Makuc DM, Kruszon-Moran D, Gindi RM, Albert M, Beresovsky V, Hamilton BE, Holmes J, Schiller J and Sengupta M: National center for health statistics guidelines for analysis of trends. Vital Health Stat 2: 1-71, 2018.

3. Malik A, Brito D and Chhabra L: Congestive heart failure. In: StatPearls. StatPearls Publishing, Treasure Island, FL, 2021.

4. Skrzypek A, Mostowik M, Szeliga M, Wilczyńska-Golonka M, Dębicka-Dąbrowska D and Nessler J: Chronic heart failure in the elderly: Still a current medical problem. Folia Med Cracov 58: 47-56, 2018.

5. Côté E: Feline congestive heart failure: Current diagnosis and management. Vet Clin North Am Small Anim Pract 47: 1055-1064, 2017.

6. Bozkurt B, Aguilar D, Deswal A, Dunbar SB, Francis GS, Horwich T, Jessup M, Kosiborod M, Pritchett AM, Ramasubbu $\mathrm{K}$, et al: Contributory risk and management of comorbidities of hypertension, obesity, diabetes mellitus, hyperlipidemia, and metabolic syndrome in chronic heart failure: A scientific statement from the American heart association. Circulation 134: e535-e578, 2016.

7. Bedi KC Jr, Snyder NW, Brandimarto J, Aziz M, Mesaros C, Worth AJ, Wang LL, Javaheri A, Blair IA, Margulies KB and Rame JE: Evidence for intramyocardial disruption of lipid metabolism and increased myocardial ketone utilization in advanced human heart failure. Circulation 133: 706-716, 2016. 
8. Piccoli MT, Gupta SK, Viereck J, Foinquinos A, Samolovac S, Kramer FL, Garg A, Remke J, Zimmer K, Batkai S and Thum T: Inhibition of the cardiac fibroblast-enriched lncRNA Meg3 prevents cardiac fibrosis and diastolic dysfunction. Circ Res 121: 575-583, 2017.

9. Souders CA, Bowers SL and Baudino TA: Cardiac fibroblast: The renaissance cell. Circ Res 105: 1164-1176, 2009.

10. Frangogiannis NG: Cardiac fibrosis: Cell biological mechanisms, molecular pathways and therapeutic opportunities. Mol Aspects Med 65: 70-99, 2019.

11. Zhang P, Su J and Mende U: Cross talk between cardiac myocytes and fibroblasts: From multiscale investigative approaches to mechanisms and functional consequences. Am J Physiol Heart Circ Physiol 303: H1385-H1396, 2012.

12. Batista-Almeida D, Martins-Marques T, Ribeiro-Rodrigues T and Girao $\mathrm{H}$ : The role of proteostasis in the regulation of cardiac intercellular communication. Adv Exp Med Biol 1233: 279-302, 2020.

13. Karki R, Man SM and Kanneganti TD: Inflammasomes and cancer. Cancer Immunol Res 5: 94-99, 2017.

14. Zhou W, Chen C, Chen Z, Liu L, Jiang J, Wu Z, Zhao M and Chen Y: NLRP3: A novel mediator in cardiovascular disease. J Immunol Res 2018: 5702103, 2018

15. van de Veerdonk FL, Joosten LA and Netea MG: The interplay between inflammasome activation and antifungal host defense. Immunol Rev 265: 172-180, 2015.

16. Man SM and Kanneganti TD: Regulation of inflammasome activation. Immunol Rev 265: 6-21, 2015.

17. Palomo J, Dietrich D, Martin P, Palmer G and Gabay C: The interleukin (IL)-1 cytokine family-Balance between agonists and antagonists in inflammatory diseases. Cytokine 76: 25-37, 2015.

18. QiuZ,He Y,Ming H,LeiS, Leng Y and XiaZY:Lipopolysaccharide (LPS) aggravates high glucose- and hypoxia/reoxygenationinduced injury through activating ROS-Dependent NLRP3 inflammasome-mediated pyroptosis in $\mathrm{H} 9 \mathrm{C} 2$ cardiomyocytes. J Diabetes Res 2019: 8151836, 2019.

19. Zhang YZ, Sui XL, Xu YP, Gu FJ, Zhang AS and Chen JH: NLRP3 inflammasome and lipid metabolism analysis based on UPLC-Q-TOF-MS in gouty nephropathy. Int J Mol Med 44: 172-184, 2019.

20. King M, Kingery J and Casey B: Diagnosis and evaluation of heart failure. Am Fam Physician 85: 1161-1168, 2012.

21. Murase T, Hattori T, Ohtake M, Abe M, Amakusa Y, Takatsu M, Murohara $\mathrm{T}$ and Nagata K: Cardiac remodeling and diastolic dysfunction in DahlS.Z-Lepr(fa)/Lepr(fa) rats: A new animal model of metabolic syndrome. Hypertens Res 35: 186-193, 2012.

22. Strutz F, Okada H, Lo CW, Danoff T, Carone RL, Tomaszewski JE and Neilson EG: Identification and characterization of a fibroblast marker: FSP1. J Cell Biol 130: 393-405, 1995.

23. Rui T, Feng Q, Lei M, Peng T, Zhang J, Xu M, Abel ED, Xenocostas A and Kvietys PR: Erythropoietin prevents the acute myocardial inflammatory response induced by ischemia/reperfusion via induction of AP-1. Cardiovasc Res 65: 719-727, 2005.

24. Yao Y, Xu X, Zhang G, Zhang Y, Qian W and Rui T: Role of HMGB1 in doxorubicin-induced myocardial apoptosis and its regulation pathway. Basic Res Cardiol 107: 267, 2012.

25. Livak KJ and Schmittgen TD: Analysis of relative gene expression data using real-time quantitative PCR and the 2(-Delta Delta C(T)) method. Methods 25: 402-408, 2001

26. Strassheim D, Dempsey EC, Gerasimovskaya E, Stenmark K and Karoor V: Role of inflammatory cell subtypes in heart failure. J Immunol Res 2019: 2164017, 2019.

27. Chen G, Bracamonte-Baran W, Diny NL, Hou X, Talor MV, Fu K, Liu Y, Davogustto G, Vasquez H, Taegtmeyer H, et al: Sca- $1^{+}$cardiac fibroblasts promote development of heart failure. Eur J Immunol 48: 1522-1538, 2018.

28. Travers JG, Kamal FA, Robbins J, Yutzey KE and Blaxall BC: Cardiac fibrosis: The fibroblast awakens. Circ Res 118: 1021-1040, 2016.

29. Malik A and Kanneganti TD: Inflammasome activation and assembly at a glance. J Cell Sci 130: 3955-3963, 2017.

30. Miteva K, Pappritz K, Sosnowski M, El-Shafeey M, Müller I, Dong F, Savvatis K, Ringe J, Tschöpe C and Van Linthout S: Mesenchymal stromal cells inhibit NLRP3 inflammasome activation in a model of Coxsackievirus B3-induced inflammatory cardiomyopathy. Sci Rep 8: 2820, 2018.

31. Bennett $M$ and Gilroy DW: Lipid mediators in inflammation Microbiol Spectr 4, no. 6, 2016.
32. Storey BC, Staplin N, Haynes R, Reith C, Emberson J, Herrington WG, Wheeler DC, Walker R, Fellström B, Wanner C, et al: Lowering LDL cholesterol reduces cardiovascular risk independently of presence of inflammation. Kidney Int 93: 1000-1007, 2018.

33. Kattoor AJ, Kanuri SH and Mehta JL: Role of Ox-LDL and LOX-1 in atherogenesis. Curr Med Chem 26: 1693-1700, 2019.

34. Stoekenbroek RM, Lambert G, Cariou B and Hovingh GK: Inhibiting PCSK9-biology beyond LDL control. Nat Rev Endocrinol 15: 52-62, 2018 .

35. Rivera AL, Estañol B, Fossion R, Toledo-Roy JC, Callejas-Rojas JA, Gien-López JA, Delgado-García GR and Frank A: Loss of breathing modulation of heart rate variability in patients with recent and long standing diabetes mellitus type II. PLoS One 11: e0165904, 2016.

36. Afsarmanesh N, Horwich TB and Fonarow GC: Total cholesterol levels and mortality risk in nonischemic systolic heart failure. Am Heart J 152: 1077-1083, 2006.

37. Foody JM, Shah R, Galusha D, Masoudi FA, Havranek EP and Krumholz HM: Statins and mortality among elderly patients hospitalized with heart failure. Circulation 113: 1086-1092, 2006.

38. Lee MMY, Sattar N, McMurray JJV and Packard CJ: Statins in the prevention and treatment of heart failure: A review of the evidence. Curr Atheroscler Rep 21: 41, 2019.

39. Bahiru E, de Cates AN, Farr MR, Jarvis MC, Palla M, Rees K, Ebrahim S and Huffman MD: Fixed-dose combination therapy for the prevention of atherosclerotic cardiovascular diseases. Cochrane Database Syst Rev 3: Cd009868, 2017.

40. Vodonos A, Ostapenko I, Toledano R, Henkin Y, Zahger D, Wolak T, Sherf M and Novack V: Statin adherence and LDL cholesterol levels. Should we assess adherence prior to statin upgrade? Eur J Intern Med 26: 268-272, 2015.

41. Sen S, Petraco R, Mayet J and Davies J: Wave intensity analysis in the human coronary circulation in health and disease. Curr Cardiol Rev 10: 17-23, 2014.

42. Tanai E and Frantz S: Pathophysiology of heart failure. Compr Physiol 6: 187-214, 2015.

43. Radulović B, Potočnjak I, Dokoza Terešak S, Trbušić M, Vrkić N, Huršidić Radulović A, Starčević N, Milošević M, Degoricija V and Frank S: Cholesterol and chloride in acute heart failure. Acta Clin Croat 58: 195-201, 2019.

44. Zhang J, Zu Y, Dhanasekara CS, Li J, Wu D, Fan Z and Wang S: Detection and treatment of atherosclerosis using nanoparticles. Wiley Interdiscip Rev Nanomed Nanobiotechnol 9: 10.1002/wnan.1412, 2017.

45. Ferrucci L and Fabbri E: Inflammageing: Chronic inflammation in ageing, cardiovascular disease, and frailty. Nat Rev Cardiol 15: 505-522, 2018

46. Sochocka M, Donskow-Łysoniewska K, Diniz BS, Kurpas D, Brzozowska $\mathrm{E}$ and Leszek J: The gut microbiome alterations and inflammation-driven pathogenesis of alzheimer's disease-a critical review. Mol Neurobiol 56: 1841-1851, 2019.

47. Mount CW, Majzner RG, Sundaresh S, Arnold EP, Kadapakkam M, Haile S, Labanieh L, Hulleman E, Woo PJ, Rietberg SP, et al: Potent antitumor efficacy of anti-GD2 CAR $\mathrm{T}$ cells in $\mathrm{H} 3-\mathrm{K} 27 \mathrm{M}^{+}$diffuse midline gliomas. Nat Med 24: $572-579,2018$

48. Sowers JL, Johnson KM, Conrad C, Patterson JT and Sowers LC: The role of inflammation in brain cancer. Adv Exp Med Biol 816: 75-105, 2014

49. Wei L, Ye H, Li G, Lu Y, Zhou Q, Zheng S, Lin Q, Liu Y, Li Z and Chen R: Cancer-associated fibroblasts promote progression and gemcitabine resistance via the SDF-1/SATB-1 pathway in pancreatic cancer. Cell Death Dis 9: 1065, 2018.

50. Kanbay M, Yerlikaya A, Sag AA, Ortiz A, Kuwabara M, Covic A, Wiecek A, Stenvinkel P and Afsar B: A journey from microenvironment to macroenvironment: The role of metaflammation and epigenetic changes in cardiorenal disease. Clin Kidney J 12: 861-870, 2019.

51. Parry TL, Melehani JH, Ranek MJ and Willis MS: Functional amyloid signaling via the inflammasome, necrosome, and signalosome: New therapeutic targets in heart failure. Front Cardiovasc Med 2: 25, 2015.

This work is licensed under a Creative Commons Attribution-NonCommercial-NoDerivatives 4.0 International (CC BY-NC-ND 4.0) License. 